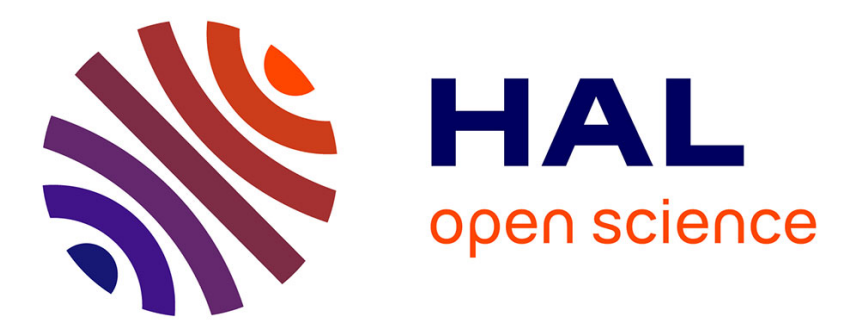

\title{
Temperature and Bias Voltage Dependence of the MPPC Detectors
}

\author{
N. Dinu, C. Bazin, C. Chaumat, C. Cheikali, A. Para, V. Puill, C. Sylvia, \\ J.-F. Vagnucci
}

\section{- To cite this version:}

N. Dinu, C. Bazin, C. Chaumat, C. Cheikali, A. Para, et al.. Temperature and Bias Voltage Dependence of the MPPC Detectors. 2010 IEEE Nuclear Science Symposium, Medical Imaging Conference and 17th Room Temperature Semiconductor Detector Worksho, Oct 2010, Knoxville, United States. IEEE, pp.215-219, 2010, 10.1109/NSSMIC.2010.5873750 。 in2p3-00537108

\section{HAL Id: in2p3-00537108 https://hal.in2p3.fr/in2p3-00537108}

Submitted on 17 Nov 2010

HAL is a multi-disciplinary open access archive for the deposit and dissemination of scientific research documents, whether they are published or not. The documents may come from teaching and research institutions in France or abroad, or from public or private research centers.
L'archive ouverte pluridisciplinaire HAL, est destinée au dépôt et à la diffusion de documents scientifiques de niveau recherche, publiés ou non, émanant des établissements d'enseignement et de recherche français ou étrangers, des laboratoires publics ou privés. 


\title{
Temperature and Bias Voltage Dependence of the MPPC Detectors
}

\author{
N. Dinu, C. Bazin. V. Chaumat, C. Cheikali, A. Para, Member, IEEE, V. Puill, C. Sylvia, J.F. Vagnucci
}

\begin{abstract}
This work reports on the characterization of the Multi-Pixel Photon Counter (MPPC) detectors as a function of the temperature and bias voltage. Devices of $1 \times 1 \mathrm{~mm}^{2}$ and $3 \times 3$ $\mathrm{mm}^{2}$ total area and $50 \times 50 \mu \mathrm{m}^{2} \mu$ cell size produced by Hamamatsu Photonics have been studied. The temperature has been varied from $-110^{\circ} \mathrm{C}$ to $-50^{\circ} \mathrm{C}$ using a cryostat cooled by liquid nitrogen and from 0 to $38^{\circ} \mathrm{C}$ using a climatic chamber. Important electrical parameters of the MPPC detectors as gain, breakdown voltage, quenching resistance, capacitance and dark count rate have been measured.
\end{abstract}

\section{INTRODUCTION}

$\mathrm{N}$ OWADAYS, the MPPC detector has become an attractive photon detector for physics applications as well as for medical imaging (e.g. ND280 \& INGRID for the T2K [1], CALICE for the ILC [2], scintillation read-out in liquid argon particle physics detectors [3], Positron Emission Tomography [4]).

The temperature and the bias voltage represent two parameters affecting important electrical characteristics of the MPPC detectors and consequently their response to the incident light. In particular, static parameters such as breakdown voltage, capacitance and quenching resistance and dynamic parameters as gain and dark count rate exhibit strong variations as a function of temperature. The dark count rate scales with the active area of the device and it has strong dependence on the applied bias voltage.

This paper presents a description of the main electrical characteristics of the MPPC detectors and their dependence of temperature. The dedicated set-ups developed for the characterization of these detectors as a function of temperature will be described. The characteristics of the MPPC detectors produced by Hamamatsu Photonics [5] with a $\mu$ cell size of $50 \times 50 \mu \mathrm{m}^{2}$ and covering a total area of $1 \times 1 \mathrm{~mm}^{2}$ and $3 \times 3 \mathrm{~mm}^{2}$ have been measured and a comparative analysis of their performances is presented.

\section{EXPERIMENTAL}

\section{A. The MPPC characteristics and work motivation}

The MPPC detector is a kind of so-called SiPM (Silicon Photomultiplier) devices [6]. It consists of hundreds of microcells ( $\mu$ cell) connected in parallel by a common silicon

N. Dinu, C. Bazin, V. Chaumat, C. Cheikali, C. Sylvia, J.F. Vagnucci are with the Laboratory of Linear Accelerator \& University Paris 11, CNRS/IN2P3, 91898 Orsay Cedex, France (telephone: +33 1 64468966, email: dinu@lal.in2p3.fr).

A. Para, is with Fermi National Accelerator Laboratory, Batavia, IL 60510-5011 USA. (telephone: 630-840-4935, e-mail: para@fnal. gov). substrate (on the rear side) and by a metal layer (on the front side). Each $\mu$ cell is represented by a $\mathrm{p}^{+} / \mathrm{n}$ junction working in Geiger-mode connected in series with its integrated passive quenching resistance.

The detectors are operated with each $\mu$ cell biased to a bias voltage $\mathrm{V}_{\text {bias }}$ above the breakdown voltage $\mathrm{V}_{\mathrm{BD}}$. The $\mathrm{V}_{\text {bias }}$ exceeds the $\mathrm{V}_{\mathrm{BD}}$ by an amount called overvoltage $\Delta \mathrm{V}=\mathrm{V}_{\text {bias }}-$ $\mathrm{V}_{\mathrm{BD}}$, which has a critical influence on detector performance (e.g. the ratio $\Delta \mathrm{V} / \mathrm{V}_{\mathrm{BD}}$ is related to the excess electric field above the breakdown level). It is expected that the $\mathrm{V}_{\mathrm{BD}}$ of a $\mathrm{p}^{+} / \mathrm{n}$ silicon junction decreases with decreasing temperature $\mathrm{T}$ (e.g. larger carrier mobility, larger ionization rates and lower potential difference for ionization at low $\mathrm{T}$ and constant electrical field [7]). Therefore, to keep constant operational conditions of the MPPC detectors (e.g. constant electrical field), the variation of the $V_{B D}$ as a function of $T$ is required to be evaluated.

A primary carrier generated in the depleted region of a MPPC $\mu$ cell by an incident photon or a thermal generated carrier produces an avalanche resulting in high current signal flowing through the junction. The continuous flow of this is limited by the quenching resistance $R_{q}$, which quenches the avalanche and reduces the $V_{\text {bias }}$ to $V_{B D}$ or below. The $V_{\text {bias }}$ is subsequently restored with a recovery time constant $\tau_{\mathrm{r}}$ depending on the values of the $\mathrm{R}_{\mathrm{q}}$ and $\mu$ cell capacitance $\mathrm{C}_{\mu \mathrm{rell}}$ $\left(\tau_{\mathrm{r}} \sim 5 \cdot \mathrm{R}_{\mathrm{q}} \times \mathrm{C}_{\mu \text { cell }}\right.$ for a $99 \%$ recharge).

The $\mathrm{R}_{\mathrm{q}}$ of the MPPC devices is fabricated by a deposition of poly-silicon. The resistance of a poly-Si varies with $\mathrm{T}$, the rate of variation depending on the dopant type and concentration [8]. Therefore, the time required to recover the $\mu$ cell operation voltage and to be able to detect another photon varies with $\mathrm{T}$ and consequently this dependence is necessary to be determined.

The effective capacitance of a $\mu$ cell $\mathrm{C}_{\mu c e l l}$ is given by the sum of the junction capacitance $\mathrm{C}_{\mathrm{d}}$ and a parasitic capacitance $\mathrm{C}_{\mathrm{q}}$, in parallel with $\mathrm{R}_{\mathrm{q}}$. Given the importance of the $\mu$ cell capacitance for the operational characteristics of the MPPC, it is very important to investigate possible variations of this parameter with the operating temperature of the device.

Other electrical parameters dominating the performances of a MPPC device in many applications are as follows: (1) the gain $(\mathrm{G})$, defined as the total charge of the Geiger avalanche divided by the electron charge; and (2) the dark count rate (DCR), defined as the number of avalanches per second registered in the absence of light.

The Geiger avalanche charge is proportional to the overvoltage $\left(\mathrm{Q}=\mathrm{C}_{\mu \text { cell }} \times \Delta \mathrm{V}\right)$. At constant $\Delta \mathrm{V}$, some variations 
of the $\mathrm{G}$ with $\mathrm{T}$ may be expected (for example as a result of variation of $\mathrm{C}_{\mu \mathrm{cell}}$ ) and they should be studied experimentally.

The DCR includes primary and secondary pulses [9]. Primary dark pulses are due to carriers thermally generated in the $\mu$ cell $\mathrm{p}^{+} / \mathrm{n}$ junction, hence the count rate increases with the $\mathrm{T}$ as does the dark current in ordinary photodiodes. This rate also increases with $\Delta \mathrm{V}$ because of two effects, namely, fieldassisted enhancement of emission rate from generation centers and an increase of the avalanche triggering probability.

Secondary dark pulses are due to afterpulsing and cross-talk effects and they may account for a large fraction of the total DCR.

During the avalanche some carriers are trapped by deep levels in the junction depletion layer and subsequently released with statistically fluctuating delay, whose mean value depends on the life time of the deep levels actually involved. Released carriers can trigger a subsequent avalanche, generating afterpulses correlated with a previous avalanche pulse. The traps lifetime depends on $T$, therefore the afterpulsing rate is expected to vary with $T$. The number of carriers captured during a Geiger avalanche increases with the total number of carriers crossing the junction, that is with the total charge of the avalanche pulse which is proportional to the $\Delta \mathrm{V}$.

In avalanching $\mathrm{p}^{+} / \mathrm{n}$ junctions the emission of hot-carrierinduced photons is a phenomenon already evidenced [10]. Such photons can trigger avalanches in adjacent $\mu$ cells generating simultaneously signals with the primary ones - a phenomenon called optical cross-talk.

Given the importance of the temperature and overvoltage for the different DCR components, an evaluation of this parameter as a function of $\mathrm{T}$ and $\Delta \mathrm{V}$ represent an important study to be performed.

\section{B. Measurements set-up}

Two experimental set-ups have been developed for the measurements presented in this paper: one using a programmable climatic chamber with $\mathrm{T}$ range $0^{\circ} \mathrm{C}<\mathrm{T}<38^{\circ} \mathrm{C}$ and a second one using a liquid nitrogen cryostat with $\mathrm{T}$ range $-110^{\circ} \mathrm{C}<\mathrm{T}<-50^{\circ} \mathrm{C}$. The $\mathrm{T}$ of the cryostat was controlled by a heater $(\mathrm{R} \sim 20 \Omega)$ and stabilized by a cryogenic control system (Cryo.con model 22) for setting the heater current while the $\mathrm{T}$ of the climatic chamber was controlled by a ventilation system. In both set-ups, the T has been monitored by a Pt100 sensor mounted close to MPPC detector and read-out by a Keithley 2000 multimeter. To obtain reproducible results, the measurements have been carried out only when a good thermal equilibrium has been attend (e.g. $\pm 0.1^{\circ} \mathrm{C}$ around assigned $\mathrm{T}$ ).

The MPPC tests in the cryogenic set-up have been carried out under vacuum conditions at $\mathrm{P} \sim 1.5 \times 10^{-3} \mathrm{mbar}$ while the tests in the climatic chamber have been performed at atmospheric pressure.

Equivalent data acquisition systems have been build to both set-ups:
- the IV static characteristics (e.g. $\mathrm{R}_{\mathrm{q}}$ ) have been obtained by a direct connection of the MPPC detector to the Keithley 2611 source-meter;

- the AC characteristics (e.g. G, $C_{\mu c e l l}, D C R$ ) have been measured biasing the MPPC detector by a Keithley 2611 source-meter and reading-out by MITEQ wideband voltage amplifier $(0.01-500 \mathrm{MHz})$ connected to a Tektronix digital oscilloscope (500 MHz, $5 \mathrm{GS} / \mathrm{s})$. The amplifier presents $50 \Omega$ input impedance, which acts as a current-to-voltage converter followed by an amplifying stage having a gain of $45 \mathrm{~dB}$. In particular for the DCR measurements at low $\mathrm{T}$, when long counting time of $10 \mathrm{~s}$ was required to measure DCR of the order of $\mathrm{Hz}$, the amplifier output signal has been connected to a counter.

To reduce the electromagnetic noise, the amplifier has been connected as close as possible to the detector. For the cryostat set-up, the amplifier has been connected outside of the cryostat to avoid the amplifier gain variation as a function of T. For the climatic chamber set-up, the amplifier gain variations have been evaluated to be less than $5 \%$ in the $\mathrm{T}$ range from $0^{\circ}$ to $38^{\circ} \mathrm{C}$ and therefore the amplifier was mounted inside of the climatic chamber.

For the automated data acquisition, the Keithley source meter and multimeter, the counter as well as the Tektronix oscilloscope have been run by LabView and $\mathrm{C}++$ programs through GPIB and USB connections. More details on the measurement of each parameter and data analysis methods will be given in the Section III.

\section{CHARACTERISTICS OF THE MPPC DEVICES}

Based on the statement that primary signals generated by a thermally generated carrier or by an incident photon in a MPPC $\mu$ cell are identical, all results presented in the following were measured in dark conditions.

The analyzed detectors present different total areas $(1 \mathrm{x} 1$ $\mathrm{mm}^{2}$ and respectively $3 \times 3 \mathrm{~mm}^{2}$ ), but the same $\mu$ cell size (e.g. 50x50 $\mu^{2}$ ). Therefore, a good uniformity as well as a very similar dependence of the measured parameters with respect to $\mathrm{T}$ are expected over analyzed detectors. Moreover, the only parameter which should present significant different values is the DCR since it is directly related to the total active area of the detector.

The $\mathrm{G}$ of the MPPC detectors has been determined from time integration of the single photoelectron signal seen on the oscilloscope during an integration window adapted on the signal shape (e.g. to collect $99 \%$ of the charge). The results of these measurements as a function of $\mathrm{V}_{\text {bias }}$ at different $\mathrm{T}$ are presented in Figs. 1. a) and b).

Independent on the measured detector, at a given $\mathrm{T}$, the $\mathrm{G}$ increases linearly with $\mathrm{V}_{\text {bias }}$ as expected (e.g. $\mathrm{G} \sim \mathrm{C}_{\mu \text { cell }} \times\left(\mathrm{V}_{\text {bias }}\right.$ - $\left.\mathrm{V}_{\mathrm{BD}}\right)$ ). The $\mathrm{V}_{\mathrm{BD}}$, determined from the intersection of the linear fits with abscise axis, shows a linear increase with $\mathrm{T}$ ranging from $-110^{\circ} \mathrm{C}$ up to $38^{\circ} \mathrm{C}$ (Fig. 2.), with a temperature coefficient of $\sim 58.5 \pm 0.5 \mathrm{mV} /{ }^{\circ} \mathrm{C}$ for both analyzed detectors.

Independent on the measured detector, at a given $\mathrm{V}_{\text {bias, }}$, the $\mathrm{G}$ decreases with $\mathrm{T}$. Since this dependence is strongly related 
to the variations of the $\mathrm{V}_{\mathrm{BD}}$ with $\mathrm{T}$, a much more uniform $\mathrm{G}$ values are expected if the $\Delta \mathrm{V}$ is maintained constant for different $\mathrm{T}$.
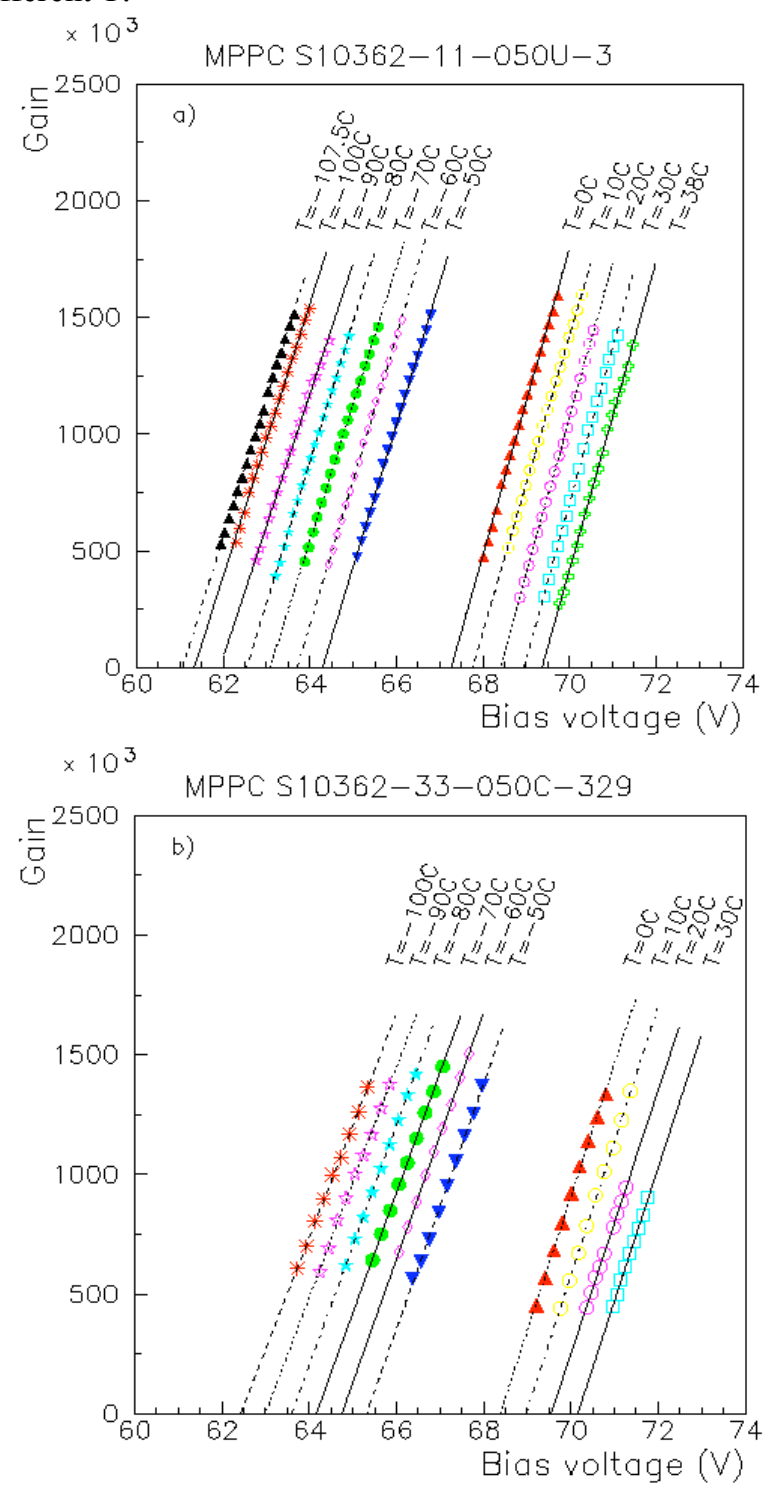

Fig. 1. The $\mathrm{G}$ vs $\mathrm{V}_{\text {bias }}$ for the MPPC of $1 \times 1 \mathrm{~mm}^{2}$ (a) and $3 \times 3 \mathrm{~mm}^{2}$ (b) at different temperatures.

Figs. 3. a) and b). present the $\mathrm{G}$ dependence of $\Delta \mathrm{V}$. The $\mathrm{G}$ increases linearly with $\Delta \mathrm{V}$, with values ranging from $2.5 \times 10^{5}$ to $1.5 \times 10^{6}$ when $\Delta \mathrm{V}$ varies from $0.5 \mathrm{~V}$ to $2.5 \mathrm{~V}$. Maximum gain variations of $20 \%$ are observed at a given $\Delta \mathrm{V}$.

Variations of the $\mathrm{G}$ with $\mathrm{T}$ at constant $\Delta \mathrm{V}$ can be interpreted as the dependence of the $\mu$ cell capacitance on $T$. The $\mathrm{C}_{\mu \text { cell }}$ is calculated from the slope of the $\mathrm{G} v \mathrm{vs} \Delta \mathrm{V}$ and their variations as a function of $\mathrm{T}$ are represented in Figs. 4. a) and b) (blue dots). The $\mathrm{C}_{\mu \text { cell }}$ shows a quadratic dependence of $\mathrm{T}$, with values increasing from 90 to $110 \mathrm{fF}$ and from 70 to $90 \mathrm{fF}$ when $\mathrm{T}$ increases from $-100^{\circ} \mathrm{C}$ to $38^{\circ} \mathrm{C}$ for the MPPC of $1 \mathrm{x} 1$ $\mathrm{mm}^{2}$ and respectively $3 \times 3 \mathrm{~mm}^{2}$.

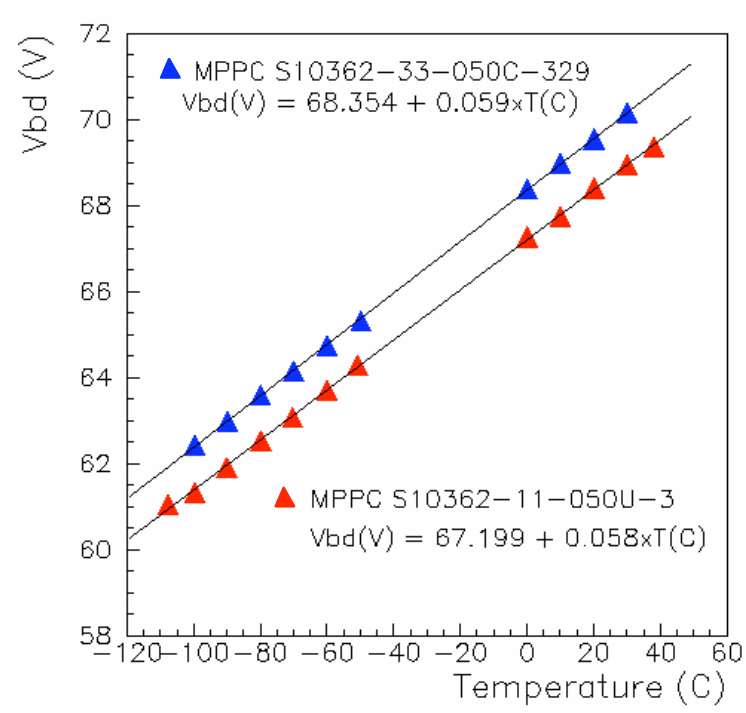

Fig. 2. The $\mathrm{V}_{\mathrm{BD}} \mathrm{vs} \mathrm{T}$ for the MPPC of $1 \mathrm{x} 1 \mathrm{~mm}^{2}$ and $3 \times 3$ $\mathrm{mm}^{2}$
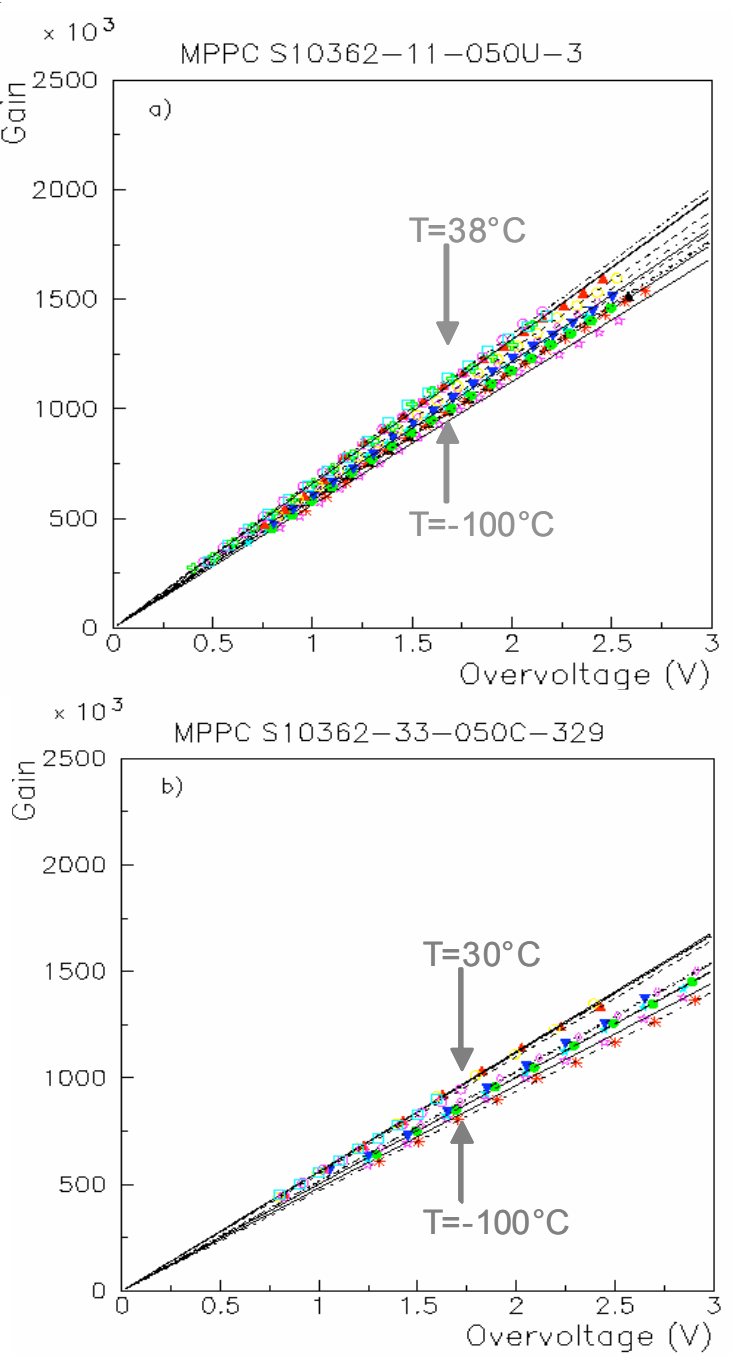

Fig. 3. The G vs $\Delta \mathrm{V}$ for the MPPC of $1 \mathrm{x} 1 \mathrm{~mm}^{2}$ (a) and $3 \times 3$ $\mathrm{mm}^{2}$ (b) at different temperatures. 

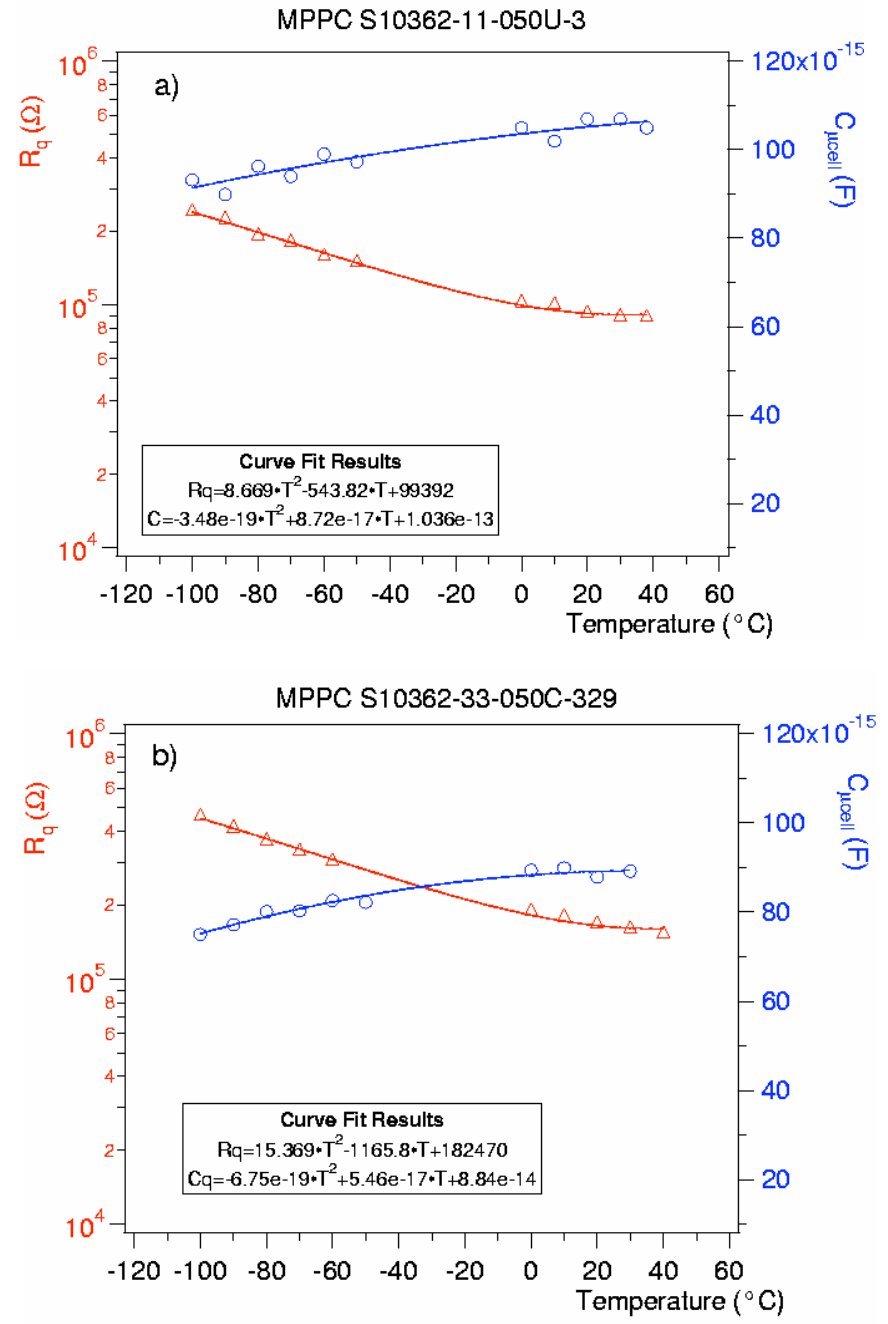

Fig. 4. The $\mathrm{R}_{\mathrm{q}} \mathrm{vs} \mathrm{C}_{\mu c e l l}$ as a function of $\mathrm{T}$ for the MPPC of $1 \times 1 \mathrm{~mm}^{2}$ (a) and $3 \times 3 \mathrm{~mm}^{2}(\mathrm{~b})$.

Figs. 4. a) and b) present also the $\mathrm{R}_{\mathrm{q}}$ (red dots) as a function of $\mathrm{T}$ (e.g. calculated from the linear fit of IV forward characteristic). The $\mathrm{R}_{\mathrm{q}}$ exhibits a quadratic variation, with decreasing values when $\mathrm{T}$ increases. The MPPC detector with an area of $1 \mathrm{x} 1 \mathrm{~mm}^{2}$ shows $\mathrm{R}_{\mathrm{q}}$ values ranging from $\sim 240 \mathrm{k} \Omega$ to $\sim 90 \mathrm{k} \Omega$ when $\mathrm{T}$ varies from $-100^{\circ} \mathrm{C}$ to $38^{\circ} \mathrm{C}$ and the detector with an area of $3 \times 3 \mathrm{~mm}^{2}$ shows $\mathrm{R}_{\mathrm{q}}$ values from $\sim 460 \mathrm{k} \Omega$ to $\sim 150 \mathrm{k} \Omega$ for the same $\mathrm{T}$ range. The higher $\mathrm{R}_{\mathrm{q}}$ values of $3 \times 3$ $\mathrm{mm}^{2}$ detector with respect to the $1 \times 1 \mathrm{~mm}^{2}$ one are probably related to changes in the fabrication of the detectors.

Variations of $\mathrm{R}_{\mathrm{q}}$ and $\mathrm{C}_{\mu \mathrm{cell}}$ with temperature leads to significant variation of the $\mu$ cells recovery time constant $\tau_{\mathrm{r}}$ and the shape of the detector signal with the T. Figs. 5. a) and b) show normalized single photoelectron signal shapes for different temperatures. Consequently, the signal integration gate, calculated as $5 \cdot \tau_{\mathrm{r}}$ for $99 \%$ recovery, decreases from 120 to $50 \mathrm{~ns}$ and from 300 to $160 \mathrm{~ns}$ for $\mathrm{T}$ increasing from $-100^{\circ} \mathrm{C}$ to $38^{\circ} \mathrm{C}$ for the MPPC of $1 \times 1 \mathrm{~mm}^{2}$ and respectively $3 \times 3 \mathrm{~mm}^{2}$ area.
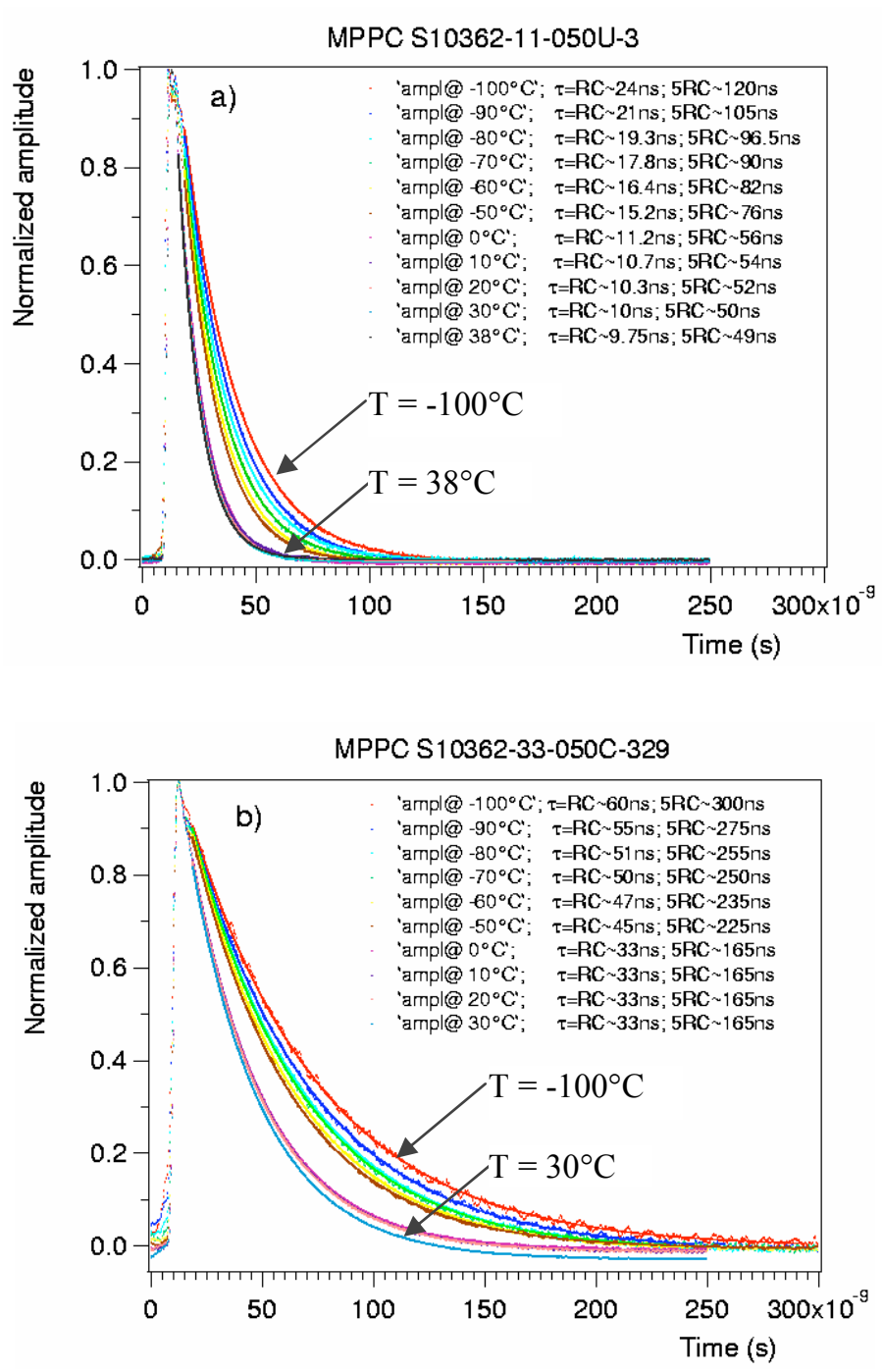

Fig. 5. The shape signal and the $\tau_{\mathrm{r}}$ for different $\mathrm{T}$ for the MPPC of $1 \mathrm{x} 1$ $\mathrm{mm}^{2}$ (a) and $3 \times 3 \mathrm{~mm}^{2}$ (b).

The DCR versus $\Delta \mathrm{V}$ has been also measured for $-100^{\circ} \mathrm{C}<\mathrm{T}<38^{\circ} \mathrm{C}$ (Figs. 6. a) and b)). At a given $\mathrm{T}$, an exponential increase of the DCR has been observed for $\Delta \mathrm{V}$ increasing up to $2.5 \mathrm{~V}$. At a given $\Delta \mathrm{V}$, the DCR increases with $\mathrm{T}$ over many orders of magnitude.

The DCR is proportional to the free carrier density. The dependence of carrier density on $\mathrm{T}$ is given by the relation: $\mathrm{A} \cdot$ $\mathrm{T}^{1.5} \exp \left(-\mathrm{E}_{\text {act }} / \mathrm{kT}\right)$, where $\mathrm{A}$ is a constant, $\mathrm{T}$ is the temperature in $\mathrm{K}, \mathrm{k}$ is the Boltzmann constant and $\mathrm{E}_{\text {act }}$ represents the thermal activation energy. Fitting the DCR versus $1 / \mathrm{T}$ in the temperature range $-60^{\circ} \mathrm{C}$ to $38^{\circ} \mathrm{C}$ with a form $\mathrm{A} \cdot \mathrm{T}^{1.5} \exp (-$ $\mathrm{E}_{\mathrm{act}} / \mathrm{kT}$ ) yields an estimation of $\mathrm{E}_{\mathrm{act}}$ of about $0.54 \mathrm{eV}$ (Fig. 7).

A deviation of the experimental points from the fitted line has been observed for $\mathrm{T}$ lower than $-60^{\circ} \mathrm{C}$, for both investigated detectors and different overvoltages. This is probably an indication of a different mechanism of generation of free carriers in the conduction band with much weaker dependence on the temperature. Similar results were recently reported in [11]. 

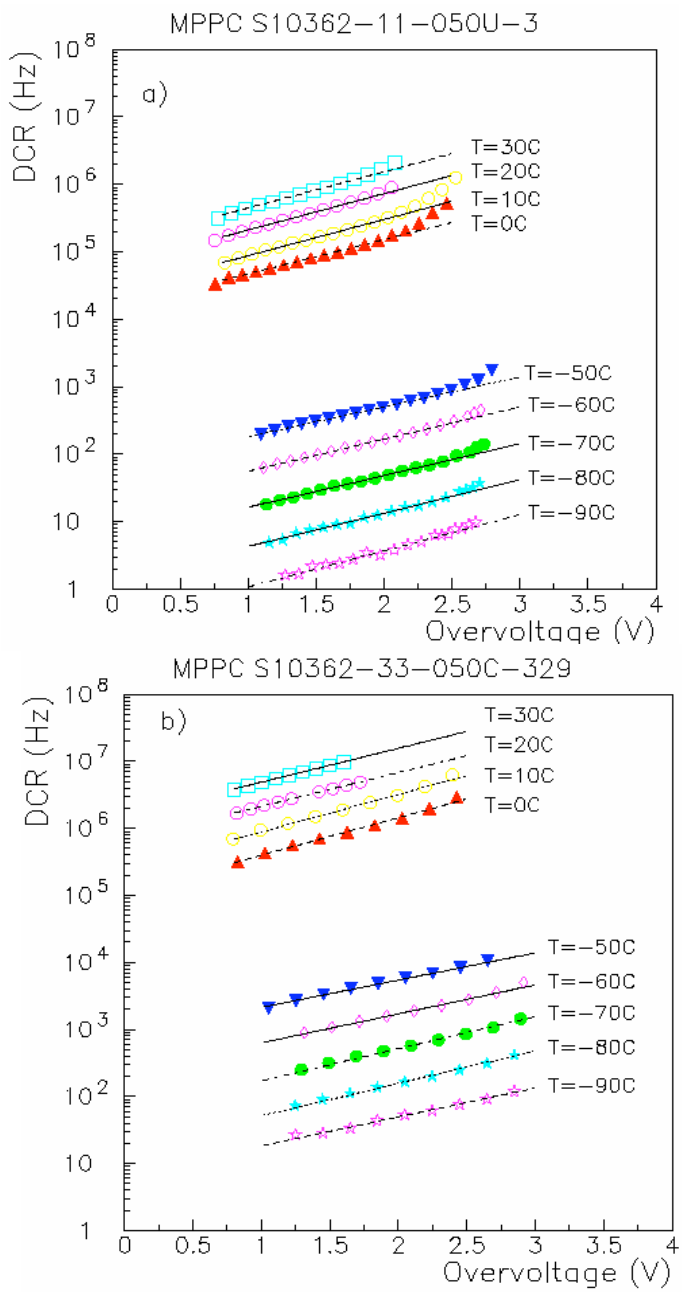

Fig. 6. The DCR vs $\triangle \mathrm{V}$ for different $\mathrm{T}$ for the MPPC of $1 \mathrm{x} 1 \mathrm{~mm}^{2}$ (a) and $3 \times 3 \mathrm{~mm}^{2}(\mathrm{~b})$.

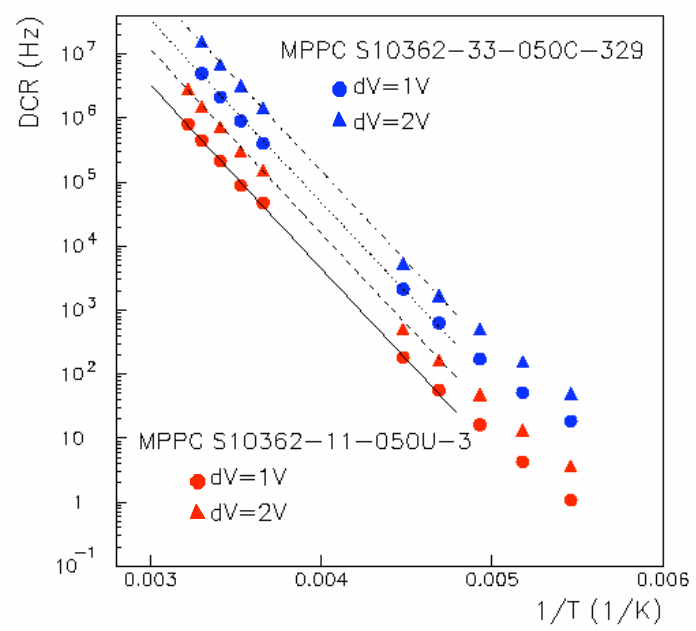

Fig. 7. The $\mathrm{DCR}$ vs $1 / \mathrm{T}$ at constant $\Delta \mathrm{V}$ (e.g. $\Delta \mathrm{V}=1 \mathrm{~V}$ and $\Delta \mathrm{V}=2 \mathrm{~V}$ ) for the MPPC of $1 \times 1 \mathrm{~mm}^{2}$ and $3 \times 3 \mathrm{~mm}^{2}$ total area

The DCR values presented in this paper include contributions from primary and secondary pulses as well. The temperature and bias voltage dependence of separate contributions are under investigation.

\section{CONCLUSIONS}

Several parameters of the Hamamatsu Photonics MPPC's exhibits dependence on the operating temperature in the temperature range from $-100^{\circ} \mathrm{C}$ to $38^{\circ} \mathrm{C}$. This temperature dependence is very similar for $1 \times 1 \mathrm{~mm}^{2}$ and $3 \times 3 \mathrm{~mm}^{2}$ devices.

Quenching resistance decreases by a factor $\sim 3$ over the investigated temperature range, whereas the $\mu$ cell capacitance increases by about $20 \%$.

Breakdown voltage increases with temperature by about $8 \mathrm{~V}$ with a rate of $58.5 \mathrm{mV} /{ }^{\circ} \mathrm{C}$. Variation of the capacitance and the quenching resistance leads to the significant change in the detector pulse shape, reducing the time constant by a factor of 2.4 over the studied temperature range.

The dark count rate drops by about six orders of magnitude in the studied temperature range. Their temperature dependence indicates that the dark rates at temperature above $-60^{\circ} \mathrm{C}$ is dominated by transitions with the effective activation energy level of about $0.54 \mathrm{eV}$. Variation of the dark count rate with temperature bellow $-60^{\circ} \mathrm{C}$ is much slower, indicating another mechanism of the free carriers generation.

\section{ACKNOWLEDGMENT}

The authors would like to thank Eng. F. Wicek, Eng. V. Tocut and Dr. M. Moniez, for allowing to borrow the cryogenic set-up from LSST experiment. This research was partially supported by LAL /IN2P3/ CNRS funding.

\section{REFERENCES}

[1] D. Orme, N. Nagai, A. Minamino, T. Nakaya, M. Yokoyama, T. Nakadaira, T. Murakami, M. Tanaka, F. Retiere, A. Vacharet, Yu Kundenko, "Development of multi-pixel photon counters for the T2K long base neutrino experiment", Nucl. Instr. \& Methods in Phys. Res., A, vol. 623, pp. 321-323, March 2010.

[2] F. Sefkow, "MGPSs for calorimeter and muon systems: requirements and first experience in the CALICE test beam", Proceedings of Science, PoS (PD07) 003, June 2007.

[3] P.K. Lightfoot, G.J. Barker, K. Mavrokoridis, Y. A. Ramachers, N. J. C. Spooner, "Characterization of a silicon photomultiplier device for applications in liquid argon based neutrino physics and dark matter searches", Journal of Instrumentation, 3 P10001, October 2008.

[4] D. R. Schaart, H. T Van Dam, S. Seifert, R. Vinke, P. Dendooven, H. Löhner, F. J Beekman, "A novel, SiPM-array-based, monolithic scintillators detector for PET", Phys. Med. Biol. vol. 54, pp. 3501-3512, 2009.

[5] http://sales.hamamatsu.com/en/home.php.

[6] V. Golovin, Z. Sadygov, M. Tarasov, N. Yusipov, Russian patent, \#1644708, 1989.

[7] S. M. Sze and Kwok K. Ng, John Wiley \& Sons, Inc., Publication, Physics of semiconductor devices, $3^{\text {rd }}$ ed., 2007, pp. 102-112.

[8] A.A. Kovalevskii, A. V. Dolbik, S. N. Voitekh, "Effect of doping on the temperature coefficient of resistance of polysilicon films", Russian Microelectronics, vol. 36, nr. 3, pp. 153-158, 2007.

[9] R. H. Haitz, "Mechanism contributing to the noise pulse rate of avalanche diodes", J. Appl. Phys., vol. 36, pp. 3123-3131, 1965.

[10] A. L. Lacaita, F. Zappa, S. Bigliardi, M. Manfredi, "On the bremsstrahlung origin of hot-carrier induced photons in silicon devices" IEEE Trans. Nucl. Dev., vol. 40, No. 3, pp. 577- 582, March 1993.

[11] G. Collazuol, M. G. Bisogni, S. Marcatili, C. Piemonte, A. Del Guerra, "Studies of silicon photomultipliers at cryogenic temperatures", Nucl. Instr. \& Methods in Phys. Res., A in press. 